\title{
Positive Correlation between Monocyte-to-Lymphocyte Ratio and C-Reactive Protein in Vitamin D Deficient Preterm Infants with Respiratory Distress Syndrome
}

\author{
Ghrahani R. ${ }^{a}$, Ghozali M. ${ }^{b}$, Sugianli A.K. ${ }^{c}$, Yuniati T. ${ }^{a}$, Judistiani R.T.Dd, Setiabudiawan B. ${ }^{a}$ \\ ${ }^{a}$ Department of Child Health, Faculty of Medicine Universitas Padjadjaran, Indonesia \\ ${ }^{b}$ Department of Biomedical Science, Faculty of Medicine Universitas Padjadjaran, Indonesia \\ 'Department of Clinical Pathology, Faculty of Medicine Universitas Padjadjaran, Indonesia \\ ${ }^{\mathrm{d}}$ Department of Public Health, Faculty of Medicine Universitas Padjadjaran, Indonesia
}

\section{ABSTRACT}

INTRODUCTION: Respiratory distress syndrome (RDS) is one of the leading causes of preterm infant mortality. Vitamin D deficiency is known as a risk factor for RDS related to infants with immature lungs leading to inflammatory exacerbations. Therefore, early diagnosis is needed to prevent RDS. This study evaluated white blood cells (WBC) ratios and C-reactive protein (CRP) among vitamin D deficient preterm infants with RDS to identify simple and prompted inflammatory markers. MATERIALS AND METHODS: A cross-sectional study involving forty preterm infants (28 to 34 -weeks gestational age) with low vitamin D levels $(25(\mathrm{OH}) \mathrm{D}<20 \mathrm{ng} / \mathrm{dL}$ ) was conducted in a neonatal ward of a hospital in Bandung, Indonesia, from February to October 2018. Two consecutive blood collections (cord blood at birth and venous blood at first week) were performed to measure cord blood vitamin D $(25(\mathrm{OH}) \mathrm{D})$ levels, complete blood count $(\mathrm{CBC})$, and CRP levels. White blood cell ratios (Monocyte-to-Lymphocyte ratio: MLR, Neutrophil-to-Lymphocyte ratio: NLR, and Platelet-to-Lymphocyte ratio: PLR) were calculated and analyzed. Association analysis was performed using Student's t-test, Mann-Whitney U and Spearman correlation tests. RESULTS: The median of 25(OH)D levels were 9.96 (7.58-15.81) ng/dL. A significant positive correlation between MLR and CRP was found in the RDS group $(r=0.576, p=0.004)$ and all the subjects $(\mathrm{r}=0.491, \mathrm{p}=0.002)$; the WBC ratio and CRP levels showed insignificant higher trends when compared to the nonRDS group. CONCLUSION: There was a positive correlation between MLR and CRP among vitamin D deficient preterm infants with RDS.

KEYWORDS: Monocyte-to-Lymphocyte ratio (MLR), preterm infants, Respiratory Distress Syndrome, Vitamin D

\section{INTRODUCTION}

Respiratory distress syndrome (RDS) is the most common complication that leads to mortality in preterm infants and is due to a lack of the surfactant in the alveoli.1,2 Previous studies reported that preterm infants are born with lower vitamin D (25(OH)D) levels

Corresponding Author:

Dr. Reni Ghrahani

Department of Child Health,

Faculty of Medicine Universitas Padjadjaran, Indonesia

Jalan Eyckman No. 38 Bandung,

Indonesia, 40161

Tel No: +628122111482

E-mail: renighrahani@yahoo.com compared to term infants. ${ }^{3-7}$ Vitamin D has a role in the surfactant secretion from the type II pneumocyte of foetal lungs and also the development of the immune response. ${ }^{8}$ According to previous studies, low vitamin $\mathrm{D}$ levels is believed to be a significant risk factor for preterm infants to develop immune deregulation. 9,10

As RDS is commonly discovered among lower gestational age infants, it is frequently seen in preterm infants with severe vitamin D deficiency. ${ }^{11,}{ }^{12}$ Vitamin D deficiency is, in fact, a global problem, even in Indonesia as a country with routine and sufficient sunlight throughout the year. Additionally, the 
deficiency is not always diagnosed early to ensure specific and timely treatments in many countries.

Vitamin D also inhibits the production of inflammatory cytokines in immune cells, therefore, low vitamin D levels can increase inflammatory reactions. ${ }^{10,13} \mathrm{RDS}$ is accompanied by an imbalanced inflammatory response, therefore by following the response of the immune cells, their levels can be a predictive indicator to RDS. Monocyte-to-lymphocyte ratio (MLR), neutrophil-tolymphocyte ratio (NLR), and Platelet-to-lymphocyte ratio (PLR) have been proposed as easy and inexpensive inflammatory markers; while C-reactive protein (CRP) is known as an acute phase reactant in inflammatory reactions. ${ }^{14-17}$

Therefore, our study was aimed to evaluate the correlation between MLR, NLR, PLR, and CRP among preterm infants with low vitamin $\mathrm{D}$ levels.

\section{MATERIALS AND METHODS}

A cross-sectional study which involved neonatal with 28 -34-week gestational age, 25(OH)D level of $\leq 20 \mathrm{ng} /$ $\mathrm{dL}^{18}$ was conducted at the Neonatology Division, Department of Child Health, Faculty of Medicine Universitas Padjadjaran and Dr Hasan Sadikin General Hospital, Bandung, Indonesia, from February to October 2018. This tertiary referral hospital facilitated 563 preterm births (28-24 weeks of gestational age) during the study period. Infants with major congenital anomaly, twins, and born from infected or diabetic mothers were excluded. Subjects who had complete vitamin $\mathrm{D}$ level and complete blood count (CBC) data were only 53 subjects. Among the subjects, there were 40 infants with low vitamin D levels. Hence, the 40 subjects of this study consisted of 27 RDS and 13 nonRDS infants.

Verbal consents were obtained from the subjects' parents or caregivers before enrolment into the study. We conducted complete history taking and detailed clinical examination for assessment of signs of respiratory distress, recorded the mode of delivery, and birth weight. Gestational age assessment was based on the date of the last menstrual period. Clinical diagnosis of the RDS was marked when the following were observed: respiratory rate $>60$ per-minute, chest wall IMJM Volume 20 No.2, Apr 2021 retraction, grunting, cyanosis in room air, radiological (+) towards RDS, PaO2 (Partial Pressure of Oxygen) levels of $50 \mathrm{mmHg}$ based on blood gas analysis, and when the infant did not recover from more than four criteria and clinical states within 24 hours. ${ }^{19,} 20$ A chest $\mathrm{X}$-ray of the postero-anterior view was performed on infants with RDS. The X-ray images were interpreted consecutively to identify the RDS by the radiologist on duty at the Radiology Department.

Cord blood and peripheral blood were collected from each eligible subject. A total of $3 \mathrm{~mL}$ cord blood was collected immediately after birth. The cord blood was directly processed in the laboratory and prepared for analysis. Sera from cord blood were stored at $-80^{\circ} \mathrm{C}$ for further analysis of vitamin D levels when blood collection was completed. A total of $1 \mathrm{~mL}$ venous blood was collected using a routine venipuncture procedure in the first week of life (day 2-7) and was examined for CBC and CRP.

CBC was performed using an automated flow-cytometry haematology analyzer (Sysmex XN series, Sysmex Corp., Japan). The ratios of circulating monocyte, neutrophil, lymphocyte, and platelet count which were marked as MLR, NLR, and PLR respectively were computed using the absolute count of each parameter from CBC. ${ }^{19,20}$ The level of $25(\mathrm{OH}) \mathrm{D}$ was measured using a competitive enzyme immunoassay method (CloudClone Corp, USA). The serum CRP level was measured using the particle-enhanced turbidimetric immunoassay (PEITA, Siemens Dimensions Series).

Collected data were analysed using the Statistical Package for Social Science (SPSS version 23 for Windows; SPSS Inc, Chicago) and then stratified into two groups, the RDS and non-RDS groups. The primary analysis of the data was aimed to access the differences in laboratory parameters between the two groups. This analysis was carried out using the Student's t-test or Mann-Whitney U statistical test.

The secondary analysis was performed to observe the correlation between MLR, NLR, PLR, and CRP level, stratified by two groups using the Spearman correlation test. A significant statistical difference was defined when the $\mathrm{p}$-value was less than 0.05 . 
All procedures were conducted in compliance with policies of the Faculty of Medicine, Universitas Padjadjaran and Dr Hasan Sadikin General Hospital, Bandung, West Java, Indonesia. This study was approved by the Health Research Ethics Committee of Faculty of Medicine, Universitas Padjadjaran Bandung (approval number: 303/UN6.KEP/EC/2018).

\section{RESULTS}

Preterm infants with RDS had significantly younger gestational age and lower birth weight than those in the non-RDS group (Table I). Vitamin D levels in both groups were lower than the normal limit $(<20 \mathrm{ng} / \mathrm{mL})$, but there was no significant difference between both groups.

Table I. Clinical and Laboratory Characteristics of Preterm infants

\begin{tabular}{lccc}
\hline \multicolumn{1}{c}{ Variables } & $\begin{array}{c}\text { RDS } \\
\mathbf{N}=\mathbf{2 7}\end{array}$ & $\begin{array}{c}\text { Non-RDS } \\
\mathbf{N}=\mathbf{1 3}\end{array}$ & $\begin{array}{c}\boldsymbol{P} \text { - } \\
\text { Value }\end{array}$ \\
\hline $\begin{array}{l}\text { Gestational } \\
\text { Age (weeks) }\end{array}$ & $32(30-33)$ & $34(32.5-34)$ & $0.025^{\mathrm{a}}$ \\
$\begin{array}{l}\text { Birth Weight } \\
\text { (grams) }\end{array}$ & $1531 \pm 294$ & $1822 \pm 292$ & $0.006^{\mathrm{b}}$ \\
$\begin{array}{l}\text { 25(OH)D } \\
\text { (ng/mL) }\end{array}$ & $11.7 \pm 5.7$ & $11.0 \pm 4.3$ & $0.708^{\mathrm{b}}$ \\
$\begin{array}{l}\text { Hemoglobin } \\
(\mathrm{g} / \mathrm{dL})\end{array}$ & $15.3 \pm 3.2$ & $16.3 \pm 2.7$ & $0.307^{\mathrm{b}}$ \\
$\begin{array}{l}\text { Red Blood Cell } \\
\left(10^{6} / \mu \mathrm{L}\right)\end{array}$ & $4.5 \pm 0.7$ & $4.9 \pm 8.8$ & $0.312^{\mathrm{b}}$ \\
$\begin{array}{l}\text { Hematocrit } \\
(\%)\end{array}$ & $45.7 \pm 10.6$ & $48.7 \pm 8.5$ & $0.434^{\mathrm{b}}$ \\
$\begin{array}{l}\text { RDW } \\
(\mathrm{CV} / 0)\end{array}$ & $16.0(15.6-17.7)$ & $17.7(16.0-18.9)$ & $0.118^{\mathrm{a}}$ \\
$\begin{array}{l}\text { Leukocyte } \\
\left(10^{3} / \mu \mathrm{L}\right)\end{array}$ & $9.3 \pm 4.2$ & $11.5 \pm 4.0$ & $0.132^{\mathrm{b}}$ \\
$\begin{array}{l}\text { Basophil } \\
\left(10^{3} / \mu \mathrm{L}\right)\end{array}$ & $0.01(0.00-0.03)$ & $0.01(0.00-0.02)$ & $0.711^{\mathrm{a}}$ \\
$\begin{array}{l}\text { Eosinophil } \\
\left(10^{3} / \mu \mathrm{L}\right)\end{array}$ & $0.12(0.06-0.26)$ & $0.26(0.05-0.50)$ & $0.530^{\mathrm{a}}$ \\
$\begin{array}{l}\text { Neutrophil } \\
\left(10^{3} / \mu \mathrm{L}\right)\end{array}$ & $4.7 \pm 3.0$ & $6.1 \pm 3.7$ & $0.190^{\mathrm{b}}$ \\
$\begin{array}{l}\text { Lymphocyte } \\
\left(10^{3} / \mu \mathrm{L}\right)\end{array}$ & $2.9 \pm 1.6$ & $3.5 \pm 1.5$ & $0.231^{\mathrm{b}}$ \\
$\begin{array}{l}\text { Monocyte } \\
\left(10^{3} / \mu \mathrm{L}\right)\end{array}$ & $1.5 \pm 0.7$ & $1.5 \pm 4.8$ & $0.974^{\mathrm{b}}$ \\
$\begin{array}{l}\text { Platelet } \\
\left(10^{3} / \mu \mathrm{L}\right)\end{array}$ & $233 \pm 107$ & $236 \pm 58$ & $0.874^{\mathrm{b}}$ \\
\hline Abrev:(a) & & & \\
\hline
\end{tabular}

Abbrev: (a) Mann-Whitney U test, data as mean \pm SD (b) Student's t-test, data as median-IQR; IQR, Inter Quartile Range; SD, Standard Deviation; RDW, Red Cell Distribution Width;

*Cord blood sample
Table I also shows the comparison of hematologic parameters in the first week of life between preterm infants with and without RDS. All haematologic parameters in the RDS group in the first week of life were lower but were not significantly different from the non-RDS group.

The preterm infants with RDS showed a higher trend of MLR, NLR, PLR, and CRP level but were not significantly different from the non-RDS group as depicted in Table II.

Table II. White Blood Cell Ratio and C-reactive protein Levels of Preterm Infants

\begin{tabular}{llll}
\hline Variables & RDS $(\mathbf{N}=\mathbf{2 7})$ & $\begin{array}{l}\text { Non-RDS } \\
(\mathbf{N}=13)\end{array}$ & $\begin{array}{l}\boldsymbol{P} \text { - } \\
\text { Value }\end{array}$ \\
\hline MLR & $0.62 \pm 0.28$ & $0.50 \pm 0.29$ & $0.142^{\mathrm{a}}$ \\
& & 1.18 & \\
NLR & $1.89(0.89-3.54)$ & $(1.06-2.68)$ & $0.798^{\mathrm{b}}$ \\
& & & \\
PLR & $94.40(58.82-111.66)$ & $\begin{array}{l}71.72 \\
(42.43-92.71)\end{array}$ & $0.197 \mathrm{~b}$ \\
& & & \\
CRP & $0.20(0.09-0.39)$ & 0.16 & $0.755^{\mathrm{b}}$ \\
& & $(0.12-0.42)$ & \\
\hline
\end{tabular}

Abbrev: (a) Student's t-test, data as mean \pm SD (b) Mann-Whitney U test, data as median-IQR; RDS, Respiratory Distress Syndrome; IQR, Inter Quartile Range; SD, Standard Deviation; MLR, Monocyte-to-lymphocyte ratio; NLR, Neutrophil-to-lymphocyte ratio; PLR, Platelet-to-lymphocyte ratio; CRP, C-reactive protein.

Therefore, the RDS group and all subjects (RDS and non-RDS) had a significant positive correlation between MLR and CRP as displayed in Table III. The RDS group, non-RDS group, and all subjects showed trends of a positive correlation between NLR, PLR, and CRP level. However, the NLR had a weak negative correlation to CRP level among the non-RDS group.

\section{DISCUSSION}

Preterm birth is a significant global health issue, as well as is vitamin $\mathrm{D}$ deficiency. This double burden contributes to RDS associated to lung immaturity. Preterm infants are born before their lungs are fully developed, while maturation is completed.1,2,21 Immature lungs inadequately produce the surfactant, which needed for reduces surface tension in the alveoli. 
Table III. Correlation between CRP level to MLR, NLR, and PLR in preterm infants

\begin{tabular}{lcccccc}
\hline & MLR & $\begin{array}{c}\mathbf{p} \\
\text { Value* }\end{array}$ & NLR & $\begin{array}{c}\mathbf{p} \\
\text { Value* }\end{array}$ & PLR & $\begin{array}{c}\mathbf{p} \\
\text { Value* }\end{array}$ \\
\hline $\begin{array}{l}\text { RDS } \\
\text { group }\end{array}$ & 0.557 & 0.009 & 0.286 & 0.208 & 0.283 & 0.210 \\
$\begin{array}{l}\text { Non- } \\
\text { RDS } \\
\text { group }\end{array}$ & 0.374 & 0.287 & -0.031 & 0.933 & 0.350 & 0.322 \\
Over all & 0.485 & 0.006 & 0.245 & 0.183 & 0.303 & 0.098 \\
\hline
\end{tabular}

*Spearman Correlation test

RDS is the most common complication of preterm infants and occurs due to the lack of surfactant in the alveoli. ${ }^{1,2}$ There is evidence that preterm infants are often born with lower vitamin D levels compared to term infants. ${ }^{3-6}$ Vitamin $\mathrm{D}$ is suggested to have a role in surfactant secretion from the type II pneumocyte (AT II cells, Alveolar Type II cells) of foetal lungs. ${ }^{22}$ On the other hand, immature fibroblast in immature lungs cannot express vitamin $\mathrm{D}$ adequately leading to inadequate surfactant secretion from the AT II cells. ${ }^{8}$ In preterm infants, RDS disease was suggested to be induced by low vitamin D levels. ${ }^{23}$ Based on these facts, the vitamin D status of preterm infants is considered to be associated with immune regulation in neonates. ${ }^{11}$ Therefore, in our study, subjects with low vitamin $\mathrm{D}$ levels were included to assess the inflammation process due to RDS in preterm infants. In RDS, there is the involvement of the inflammatory process and the inflammation is caused by lung immaturity and lack of surfactant secretion. The process cascade of RDS is as follows: lack of pulmonary compliance, atelectasis, reduced gas exchange, severe hypoxemia and hypercarbia. The integrity of the endothelial and epithelial are subsequently damaged, and this results in the stimulation of local and systemic inflammation. ${ }^{24-26}$

Our study showed that preterm infants with RDS were of younger gestational age and had lower birth weight than those in the non-RDS group. This finding is in accordance with previous studies which revealed that the risk of RDS decreases with increasing gestational age. ${ }^{27-29}$ The proportion of RDS infants in our study (27/40 subjects) was higher than in a previous study which reported the RDS affects in one-third of infants born between 28 to 34 weeks' of gestation. ${ }^{20}$ The proportion of RDS infants was higher because only infants with low vitamin D levels were included in this study. his study also showed that all haematologic parameters in preterm infants with RDS tended to be lower compared with the non-RDS group. This finding is similar to a previous study which revealed that because RDS was commonly found in younger gestational age, lower haemoglobins and fewer immune cells, such as neutrophils, lymphocytes, and monocytes were reported. ${ }^{30,31}$ Our study also demonstrated lower platelet counts in the RDS group compared to the non-RDS group. Additionally, similar to the findings of a prospective study by Kohelet et al (1990), RDS severity was strongly associated with platelet count reduction in the first few days after birth. Platelet count was often decreased in high-risk neonates, such as those with perinatal asphyxia, umbilical catheters, hyperbilirubinemia, polycythaemia, sepsis, intracranial bleeding and undergoing phototherapy.32 On the contrary, Chen et al (2019), in a retrospective study reported different results from Kohelet et al (1990), . Here it was demonstrated that platelet, neutrophil and monocyte counts at birth are higher in infants with RDS but basophil and lymphocyte counts were lower. ${ }^{33}$

Essential components of the innate immune response are circulating white blood cells (WBC), e.g. neutrophil, lymphocyte, and monocyte. Ratios of the WBC (NLR, MLR, and PLR) have been proposed as potential markers of general inflammatory responses for predicting survival of patients with various diseases, such as malignancies, autoimmune and infectious diseases. $34,14-16,35$ Interestingly, our study demonstrated that MLR, NLR, PLR and CRP level of the RDS group were higher compared to the non-RDS group (Table II). Our study also showed a significant correlation between MLR and CRP level, which are inflammation-related evidence that bridges RDS and lung immaturity (Table III). These findings also suggested that the innate immunity is crucial during the neonate period, since the adaptive immunity is not fully developed. ${ }^{13}$ Until today, the notions regarding MLR, NLR, and PLR in preterm infants are still scarce, while the CRP is considered as a primary inflammatory marker. Monocytes are an important component of peripheral blood as well, hence the increase of monocyte count describes increased monocyte migration from the bone marrow to the peripheral blood due to the inflammatory response. ${ }^{30,36}$ The ratio of monocyte to lymphocytes will be altered and will reflect an unfavourable balance involving 
monocytes and a favourable prognostic outcome involving lymphocytes, hence MLR is considered as an indicator of systemic inflammation. ${ }^{37}$

The correlation between MLR and CRP level suggests the strengthening of MLR utilization as an alternative inflammatory marker. This finding is expected to improve the health service because many hospitals in developing countries do not have the facilities to examine CRP as a common inflammatory marker. The NLR associated as a marker of a pro-inflammatory state is also widely known as a haematological marker for systemic inflammation. There are associations between a higher neutrophil percentage or lower lymphocyte percentage with the increased inflammatory response in several diseases. ${ }^{38,39}$ The use of NLR which quantitates neutrophilia (an indicator of inflammation) and lymphopenia (an indicator of physiologic stress) is a valuable prognostic gage for evaluating patients with systemic inflammation. ${ }^{40,41}$ Porata and Tse et al. (2012) reported that PLR is another indicator of systemic inflammation that has been validated as a prognostic predictor in some tumours ${ }^{42}$ Meanwhile, previous studies also reported platelet in the involvement of the inflammatory process. ${ }^{43-46}$ Platelets play an important role in premature birth-related diseases, including RDS.47,48 The higher trend in CRP level as the most frequently used inflammatory marker defined a higher inflammatory process in the RDS group compared to the non-RDS group.

One limitation of this study is that it was a crosssectional study which only involved 40 preterm infants with complete CBC data and low vitamin D levels. Further research is mandatory to explore the leucocyte activity related to inflammation and low vitamin D levels.

In conclusion, WBC ratios involved in inflammation process show correlation with the CRP among vitamin $\mathrm{D}$ deficient preterm infants with RDS. Therefore, we propose that performing $\mathrm{WBC}$ ratio analysis are important in recognising RDS in preterm infants.

\section{RECOMMENDATIONS}

Monocyte-to-Lymphocyte Ratio is a potential marker to assess the inflammatory process leading to RDS, particularly among vitamin $\mathrm{D}$ deficient preterm infants. Further research is imperative to involve other perinatal related variables to have an integrated prevention and treatment approach.

\section{ACKNOWLEDGEMENTS}

We are grateful to the participants and the Neonatology Division Department of Child Health Dr Hasan Sadikin General Hospital in this study for their support in data collection. This study was funded by a grant from Riset Kompetensi Dosen UNPAD, Universitas Padjadjaran number: 855/UN6.3.1/PL/2017.

\section{Author Contributions}

Reni Ghrahani conceptualized, conducted the study, provided instruments of the data collection, coordinated and supervised data collection, performed the analyses, composed and edited the manuscript.

Mohammad Ghozali, Adhi Kristianto Sugianli, Raden Tina Dewi Judistiani, and Tetty Yuniati designed the study, checked, and revised the manuscript;

Budi Setiabudiawan conceived the study and reviewed the manuscript.

\section{CONFLICTS OF INTEREST}

The authors declare no conflict of interest.

\section{REFERENCES}

1. Grgić G, Muharemovic E, Ljuca D, et al. Frequency of neonatal complications after premature delivery. Journal of Health Sciences 2013; 3 (1):65-69. DOI: 10.17532/jhsci.2013.32.

2. Boyle AK, Rinaldi SF, Norman JE, et al. Preterm birth: Inflammation, fetal injury and treatment strategies. Journal of Reproductive Immunology 2017; 119: 62-66. 3. Park S-H, Lee G-M, Moon J-E, et al. Severe vitamin $\mathrm{D}$ deficiency in preterm infants: maternal and neonatal clinical features. Korean Journal of Pediatrics 2015; 58: 427-433.

4. McCarthy RA, McKenna MJ, Oyefeso O, et al. Vitamin D nutritional status in preterm infants 
and response to supplementation. Br J Nutr 2013; 110: 156-163.

5. Dawodu A and Nath R. High prevalence of moderately severe vitamin $\mathrm{D}$ deficiency in preterm infants. Pediatrics international : official journal of the Japan Pediatric Society 2011; 53: $207-$ 210. 2010/07/30. DOI: $10.1111 /$ j.1442200X.2010.03209.x.

6. Thota C, Menon R, Fortunato SJ, et al. 1,25Dihydroxyvitamin D Deficiency Is Associated With Preterm Birth in African American and Caucasian Women. Reproductive Sciences 2014; 21: 244-250. DOI: 10.1177/1933719113493513.

7. Burris HH, Van Marter LJ, McElrath TF, et al. Vitamin D status among preterm and full-term infants at birth. Pediatr Res 2014; 75: 75-80. 2013/10/15. DOI: 10.1038/pr.2013.174.

8. Lykkedegn S, Sorensen GL, Beck-Nielsen SS, et al. The impact of vitamin $\mathrm{D}$ on fetal and neonatal lung maturation. A systematic review. American Journal of Physiology - Lung Cellular and Molecular Physiology 2015; 308: L587-L602. DOI: 10.1152/ ajplung.00117.2014.

9. Sava F, Treszl A, Hajdu J, et al. Plasma vitamin D levels at birth and immune status of preterm infants. Immunobiology 2016; 221: 1289-1292. DOI: 10.1016/j.imbio.2016.06.001.

10. Aranow C. Vitamin D and the Immune System. Journal of investigative medicine: the official publication of the American Federation for Clinical Research 2011; 59: 881-886. DOI: 10.231/JIM.0b013e31821b8755.

11. Pacifici GM. Effects of Vitamin D in Neonates and Young Infants. International Journal of Pediatrics 2016; 4: 1273-1285. DOI: $10.22038 /$ ijp.2016.6325.

12. Ataseven F, Aygün C, Okuyucu A, et al. Is Vitamin D Deficiency a Risk Factor for Respiratory Distress Syndrome? International Journal for Vitamin and Nutrition Research 2013; 83: 232-237. DOI: 10.1024/0300-9831/a000165.

13. Walker VP, Zhang X, Rastegar I, et al. Cord Blood Vitamin D Status Impacts Innate Immune Responses. The Journal of Clinical Endocrinology and Metabolism 2011; 96: 1835-1843. DOI: 10.1210/ jc.2010-1559.

14. Djordjevic D, Rondovic G, Surbatovic M, et al. Neutrophil-to-Lymphocyte Ratio, Monocyte-toLymphocyte Ratio, Platelet-to-Lymphocyte Ratio, and Mean Platelet Volume-to-Platelet Count Ratio as Biomarkers in Critically Ill and Injured Patients: Which Ratio to Choose to Predict Outcome and Nature of Bacteremia? Mediators of inflammation 2018; 2018: 3758068. 2018/08/18. DOI: $10.1155 / 2018 / 3758068$.

15. Xiang J, Zhou L, Li X, et al. Preoperative Monocyte-to-Lymphocyte Ratio in Peripheral Blood Predicts Stages, Metastasis, and Histological Grades in Patients with Ovarian Cancer. Translational Oncology 2017; 10: 33-39. DOI: https://doi.org/10.1016/j.tranon.2016.10.006.

16. Huang $\mathrm{Y}$, Deng $\mathrm{W}$, Zheng S, et al. Relationship between monocytes to lymphocytes ratio and axial spondyloarthritis. International immunopharmacology 2018; 57: 43-46. 2018/02/23. DOI: 10.1016/ j.intimp.2018.02.008.

17. Adorini L and Penna G. Control of autoimmune diseases by the vitamin $\mathrm{D}$ endocrine system. Nature clinical practice Rheumatology 2008; 4: 404-412. 2008/07/03. DOI: 10.1038/ncprheum0855.

18. Rosen CJ, Abrams SA, Aloia JF, et al. IOM committee members respond to Endocrine Society vitamin D guideline. The Journal of Clinical Endocrinology and Metabolism; 97: 1146-1152. 2012/03/24. DOI: 10.1210/jc.2011-2218.

19. Holme $\mathrm{N}$ and Chetcuti P. The pathophysiology of respiratory distress syndrome in neonates. Paediatrics and Child Health 2012; 22: 507-512. DOI: 10.1016/j.paed.2012.09.001.

20. Hermansen CL and Lorah KN. Respiratory distress in the newborn. American family physician 2007; 76: 987-994. 2007/10/25.

21. Blencowe $\mathrm{H}$, Cousens $\mathrm{S}$, Chou D, et al. Born too soon: the global epidemiology of 15 million preterm births. Reproductive bealth 2013; 10 Suppl 1: S2. 2014/03/15. DOI: 10.1186/1742-4755-10-s1s2.

22. Aly $\mathrm{H}$ and Abdel-Hady H. Vitamin $\mathrm{D}$ and the neonate: An update. Journal of Clinical Neonatology 2015; 4: 1-7. Review Article. DOI: 10.4103/22494847.151155.

23. Boskabadi H, Mamoori G, Khatami SF, et al. Serum level of vitamin $\mathrm{D}$ in preterm infants and its association with premature-related respiratory complications: a case-control study. Electronic physician 2018; 10: 6208-6214. 2018/03/29. DOI: 10.19082/6208. 
24. Varvarigou AA, Thomas I, Rodi M, et al. Respiratory distress syndrome (RDS) in premature infants is underscored by the magnitude of Th1 cytokine polarization. Cytokine 2012; 58: 355-360. 2012/04/03. DOI: 10.1016/ j.cyto.2012.03.005.

25. Speer C. Neonatal Respiratory Distress Syndrome: An Inflammatory Disease? Neonatology 2011; 99: 316-319. DOI: 10.1159/000326619.

26. Nupponen I, Kuuliala A, Siitonen S, et al. Cord blood monocytes, neutrophils and lymphocytes from preterm and full-term neonates show multiple aberrations in signalling profiles measured using phospho-specific whole-blood flow cytometry. Scand J Immunol 2013; 78: 426438. 2013/07/03. DOI: 10.1111/sji.12094.

27. Liu J, Cao HY, Wang HW, et al. The Role of Lung Ultrasound in Diagnosis of Respiratory Distress Syndrome in Newborn Infants. Iranian journal of pediatrics 2015; 25: e323. 2015/07/23. DOI: $10.5812 /$ ijp.323.

28. Faghani A, Niknafs P, Afjeh S, et al. Management of Neonatal Respiratory Distress Syndrome Employing ACoRN Respiratory Sequence Protocol versus Early Nasal Continuous Positive Airway Pressure Protocol. 2014; 24: 57-63. Research Article 2014-01-02.

29. Warren JB and Anderson JM. Newborn respiratory disorders. Pediatrics in Review 2010; 31: 487-495; quiz 496. 2010/12/03. DOI: 10.1542/ pir.31-12-487.

30. Melville JM and Moss TJ. The immune consequences of preterm birth. Frontiers in neuroscience 2013; 7: 79. 2013/06/05. DOI: 10.3389 /fnins. 2013.00079 .

31. El-Gamal Y, El-Owaidy R, Hamza M, et al. Neutrophil functions in late preterm neonates with respiratory distress syndrome. Egypt J Pediatr Allergy Immunol 2015;13(2):39-44.

32. Kohelet D, Perlman M, Hanna G, et al. Reduced platelet counts in neonatal respiratory distress syndrome. Biol Neonate 1990; 57: 334-342. 1990/01/01. DOI: 10.1159/000243210.

33. Chen X, Li H, Qiu X, et al. Neonatal hematological parameters and the risk of moderate-severe bronchopulmonary dysplasia in extremely premature infants. BMC Pediatrics 2019; 19: 138. DOI: 10.1186/s12887-019-1515-6.
34. Hu Y-X, Xu X-X, Shao Y, et al. The prognostic value of lymphocyte-to-monocyte ratio in retinopathy of prematurity. International journal of ophthalmology 2017; 10: 1716-1721. DOI: 10.18240/ijo.2017.11.13.

35. Gasparyan AY, Ayvazyan L, Mukanova U, et al. The Platelet-to-Lymphocyte Ratio as an Inflammatory Marker in Rheumatic Diseases. Annals of laboratory medicine 2019; 39: 345-357. 2019/02/28. DOI: 10.3343/alm.2019.39.4.345.

36. Shi $\mathrm{C}$ and Pamer EG. Monocyte recruitment during infection and inflammation. Nature reviews Immunology 2011; 11: 762-774. 2011/10/11. DOI: $10.1038 /$ nri3070.

37. Li J, Jiang R, Liu W-S, et al. A Large Cohort Study Reveals the Association of Elevated Peripheral Blood Lymphocyte-to-Monocyte Ratio with Favorable Prognosis in Nasopharyngeal Carcinoma. PLOS ONE 2013; 8: e83069. DOI: 10.1371/journal.pone.0083069.

38. Temel MT, Coskun ME, Akbayram S, et al. Association between neutrophil/lymphocyte ratio with ductus arteriosus patency in preterm newborns. Bratislavske lekarske listy 2017; 118: 491 494. 2017/10/21. DOI: 10.4149/bll_2017_094.

39. Aydin M, Yuksel M, Yildiz A, et al. Association between the neutrophil to lymphocyte ratio and prehypertension. Bratislavske lekarske listy 2015; 116: 475-479. 2015/09/10.

40. Karaca EE, Özmen MC, Ekici F, et al. Neutrophil -to-lymphocyte ratio may predict progression in patients with keratoconus. Cornea 2014; 33: 11681173. DOI: $10.1097 /$ ico.0000000000000260.

41. Ozgonul C, Sertoglu E and Gokce G. Accurate use of neutrophil/lymphocyte ratio in patients with keratoconus. Cornea 2015; 34: e4-5. DOI: 10.1097/ico.0000000000000321.

42. Porrata LF, Ristow K, Colgan JP, et al. Peripheral blood lymphocyte/monocyte ratio at diagnosis and survival in classical Hodgkin's lymphoma. Haematologica 2012; 97: 262-269. 2011/10/14. DOI: 10.3324/haematol.2011.050138.

43. Wagner DD and Burger PC. Platelets in inflammation and thrombosis. Arteriosclerosis, thrombosis, and vascular biology 2003; 23: 2131-2137. 2003/09/23.DOI:10.1161/01.Atv. 0000095974.95122.Ec. 
44. Sprague DL, Elzey BD, Crist SA, et al. Plateletmediated modulation of adaptive immunity: unique delivery of CD154 signal by plateletderived membrane vesicles. Blood 2008; 111: 5028 -5036. 2008/01/17. DOI: 10.1182/blood-200706-097410.

45. Semple JW and Freedman J. Platelets and innate immunity. Cellular and molecular life sciences: CMLS 2010; 67: 499-511. 2009/12/18. DOI: 10.1007/ s00018-009-0205-1.

46. Smyth SS, McEver RP, Weyrich AS, et al. Platelet functions beyond hemostasis. Journal of thrombosis and haemostasis: JTH 2009; 7: 1759-1766.

2009/08/21. DOI: $10.1111 /$ j.1538-

7836.2009.03586.x.

47. Canpolat FE, Yurdakok M, Armangil D, et al. Mean platelet volume in neonatal respiratory distress syndrome. Pediatrics international : official journal of the Japan Pediatric Society 2009; 51: 314316. 2009/04/22. DOI: $10.1111 /$ j.1442200X.2009.02820.x.

48. Esiaba I, Mousselli I, M. Faison G, et al. Platelets in the Newborn. Neonatal Medicine 2019. DOI: doi:10.5772/intechopen.86715. 